\title{
REPERCUSSÕES BIOPSICOSSOCIAIS DE UMA CAPACITAÇÃO EM PRÁTICAS CORPORAIS / ATIVIDADES FÍSICAS EM UMA UNIDADE DE SAÚDE DA FAMÍLIA
}

\author{
BIOPSYCHOSOCIAL REPERCUSSIONS OF AN EDUCATIONAL TRAINING
}

REGARDING PHYSICAL ACTIVITY IN A FAMILY HEALTH UNIT

\author{
Anita de Cássia Melinski ${ }^{1}$ \\ Ricardo Luís Fernandes Guerra ${ }^{2}$ \\ Glauco Nunes Souto Ramos ${ }^{3}$ \\ Ana Cláudia Garcia de Oliveira Duarte ${ }^{4}$ \\ Recebido em: 24 mar. 2018 \\ Aceito em: 16 jun. 2018
}

RESUMO: A Estratégia Saúde da Família (ESF) visa mudar o padrão vigente de uma assistência marcada por ações curativas para outro com maior ênfase na promoção e prevenção. Entretanto, a atividade física, parte integrante dessas ações, nem sempre é de conhecimento dos profissionais da equipe mínima da ESF. Neste sentido, com a criação do Núcleo de Apoio a Saúde da Família, o profissional de Educação Física (PEF) passou a ter maior destaque nas práticas de saúde em geral, compondo a equipe de apoio da Unidade de Saúde da Família (USF), garantindo suporte para realização de práticas corporais / atividades físicas (PCAF) inclusive dos demais trabalhadores, uma vez que o ambiente laboral poderá afetar negativamente seus desempenhos profissionais. Até o presente momento, a literatura não traz referências a respeito das repercussões de uma capacitação com esse tema em profissionais de diferentes áreas de uma USF. Assim, este estudo de campo exploratório de caráter qualitativo objetivou analisar as repercussões de uma capacitação realizada por um PEF sobre assuntos referentes às PCAF na saúde e afetividade de profissionais em uma USF. Participaram nove profissionais atuantes em uma USF, selecionados por amostragem deliberada por variedades de tipo. Para a coleta de dados, foi realizada entrevista semidirigida. Para a análise e interpretação dos dados, foi utilizada a análise de conteúdo apoiada no referencial teórico do cuidando do cuidador mediante trajetória ideográfica-nomotética. A capacitação realizada por um PEF sobre assuntos referentes às PCAF em uma USF implicou em repercussões positivas na saúde e afetividade dos profissionais participantes.

Palavras-chave: Educação Física e Treinamento. Estratégia Saúde da Família. Promoção da Saúde. Saúde do Trabalhador.

ABSTRACT: The Family Health Strategy (ESF) aims to change the assistance standard, which was marked by curative actions, to a new way to offer care with emphasis in health promotion and prevention. However, physical activity is an essential component of these actions, and it is not always a common knowledge among the minimum ESF team. Therefore, with the implementation of the Support Nucleus to the Family Health Strategy, the Physical Education professional (PEF) started playing a relevant role in general health practices, who is indicated to be

\footnotetext{
1 Universidade Federal de São Carlos.

2 Universidade Federal de São Paulo - Campus Baixada Santista.

3 Universidade Federal de São Carlos.

4 Universidade Federal de São Carlos.
} 
present in the support team to the Family Health Unit (USF), ensuring support to physical activity practices (PCAF), including for the other team members, since workplace may affect negatively their performance. Nevertheless, until the present moment, literature regarding the long-term repercussions of an educational training to USF professionals were not found. The aim of this exploratory qualitative study was to analyse the health and affectivity repercussions of a PCAF educational training provided by a PEF and offered to professionals in an USF. Nine USF professionals participated, who were selected through multiple-types deliberated sampling. Semistructured interviews were conducted. Content analysis was used to interpret the data, supported by caring the carer theoretical referential, using an ideographic-nomothetic trajectory. An educational training conducted by a PEF regarding PCAF in a USF led to positive health and affectivity repercussions on participants.

Keywords: Physical Education and Training. Family Health Strategy. Health Promotion. Occupational Health.

\section{INTRODUÇÃO}

A Constituição Federal de 1988, marco da reforma do sistema de saúde brasileiro, institucionalizou como dever do Estado a garantia de saúde para toda a população nacional, criando o Sistema Único de Saúde (SUS), posteriormente regulamentado pelas leis $\mathrm{n}^{\circ}$ 8.080 e no 8.142 de 1990 (BRASIL, 2011). Além disso, incorporou novas dimensões ao conceito de saúde, como alimentação, emprego, educação, lazer e moradia (BRASIL, 2011).

O SUS tem se estruturado desde então de forma a prover melhores serviços de saúde e, consequentemente, melhor qualidade de vida para a nação brasileira. Para tanto, desenvolve ações para que se cumpram seus princípios organizativos e doutrinários de universalidade, integralidade, equidade, participação social, descentralização, regionalização e hierarquização (BRASIL, 2011), englobando neste último a organização dos serviços em níveis de complexidade crescente (BRASIL, 1990), isso é, primário, secundário e terciário.

A Atenção Primária à Saúde (APS) é definida como um conjunto de ações de saúde tanto no âmbito individual quanto coletivo e deve ser o primeiro contato do usuário em uma rede assistencial, caracterizada, entre outros aspectos, pela integralidade, continuidade do cuidado e coordenação da atenção dentro do sistema (BRASIL, 2006, 2009).

O Programa Saúde da Família (PSF), atualmente denominado Estratégia Saúde da Família (ESF), é uma das vertentes brasileiras da APS, indo ao encontro dos citados princípios, tendo sido criado pelo Ministério da Saúde em 1994 com o intuito de reorganizar os serviços de saúde, mudando a abordagem médico-centrada predominante, caracterizada por uma assistência marcada por ações curativas e visão biologicista do processo saúde-doença, para outra em que o cuidado seja centrado na família e em seu ambiente físico e social, com condutas que vão além de práticas curativas, destacando, dessa forma, as ações de promoção e prevenção, permitindo uma concepção ampliada desse binômio (BRASIL, 1997a, 2009; MERHY et. al., 2007). Isso exige olhares que 
extrapolem os muros das unidades de saúde, estendendo-os para o local onde os indivíduos vivem, trabalham e se relacionam (BRASIL, 1997a, 2010).

Assim sendo, é recomendado que a estratégia de atenção proposta seja formada por uma equipe multidisciplinar mínima, também chamada de equipe de referência, composta por médico de família ou generalista, enfermeiro, auxiliar de enfermagem e agente comunitário de saúde (ACS), podendo incorporar outros profissionais com base nas demandas e características da organização dos serviços locais, os quais constituirão a equipe de apoio (BRASIL, 1997a, 2009).

Em 2006, o Ministério da Saúde instituiu a Política Nacional de Promoção da Saúde (PNPS) com o objetivo de promover a qualidade de vida da população brasileira e diminuir os riscos e vulnerabilidades relacionados à saúde ocasionados por determinantes e condicionantes como educação, habitação, condições de trabalho, modos de viver, lazer, cultura, entre outros (BRASIL, 2010). Para isso, valorizou ações de promoção, informação e educação em saúde voltadas, dentre outras, às práticas corporais / atividade física (PCAF), principalmente no âmbito da atenção básica (BRASIL, 2010).

Em 2008, criou, também, o Núcleo de Apoio a Saúde da Família (NASF) visando aumentar as ações da APS por meio do apoio à inserção da ESF na rede de cuidados, ampliando sua abrangência, regionalização, territorialização e resolutividade (BRASIL, 2009). Sua equipe deve ser formada por profissionais de diferentes áreas que atuarão de formas variadas em conjunto com a equipe de referência de determinadas USF em seus respectivos territórios adscritos (ex.: atendimento compartilhado e interdisciplinar, apoio aos grupos e ações junto aos equipamentos públicos), podendo o profissional de Educação Física (PEF) compor este quadro (BRASIL, 2009). Essa dinâmica preza pela criação de espaços que favoreçam o diálogo, o encontro de elementos comuns e a valorização das especificidades de cada área (BRASIL, 2009).

Com a adoção de tais medidas, o PEF passou a ter maior destaque na perspectiva de reflexão das práticas de saúde em geral, bem como na construção de redes de cuidado integral, transversalidade das políticas de saúde e direito ao lazer (BRASIL, 2009), possibilitando o auxílio às ações que almejam, principalmente, a promoção da saúde e prevenção de doenças, justificando sua inserção na equipe de apoio.

Tal inserção tem por propósito servir de ferramenta para a conscientização da comunidade e do próprio serviço da importância de cuidar do corpo por meio da realização de PCAF (FREITAS, 2007) construídas a partir de componentes específicos (políticos, históricos, culturais, sociais e econômicos) de seu respectivo território, possibilitando uma elucidação da relação desse cuidado com a saúde (BRASIL, 2009). É nesse ponto que o PEF se faz essencial: ele deve evitar a imposição das ações englobando conteúdos clássicos da Educação Física e favorecer àquelas envolvendo PCAF que reflitam as vontades e necessidades do público-alvo, o que possibilitará uma maior identificação e adesão das atividades ofertadas e, consequentemente, ampliação da autonomia do sujeito (BRASIL, 2009; FREITAS, 2007). Além disso, deve utilizar-se do aspecto lúdico atribuído à atividade física como subsídio para interação do grupo, valorizando o cuidado em todos os 
âmbitos consigo mesmo e com o próximo (FREITAS, 2007).

Estas explanações sinalizam que utilizar as PCAF somente para atuar na clínica, ou seja, com os indivíduos que já possuem patologias prévias, provocará um reducionismo da ampla gama de aspectos que as mesmas englobam, além de não contemplar questões relacionadas à promoção e prevenção da saúde na APS preconizadas pelo SUS, sendo indicado, portanto, a convergência dessas vertentes (FREITAS, 2007). Ademais, quando se trata de trabalhadores, o ambiente laboral os expõe a níveis elevados de estresse, o que com grande chance afetará negativamente seus desempenhos profissionais, justificando a existência de espaços que objetivem o cuidado voltado para eles. Nessa direção, tendo o PEF competências advindas de sua prática de formação que podem contribuir para que esse cuidado aos profissionais seja alcançado de forma satisfatória, é indicado que ele componha a equipe multiprofissional das USF (BRASIL, 2009), não agindo de forma desvinculada, mas sim complementando as ações já existentes no serviço (FREITAS, 2007).

Entretanto, até o presente momento, não foram encontrados relatos na literatura a respeito das repercussões de uma capacitação em PCAF na saúde e afetividade de profissionais de diferentes áreas de uma USF, fazendo com que o presente estudo represente um empreendimento nesta direção, podendo oferecer subsídios para novas intervenções semelhantes junto às USF e demais equipamentos da atenção básica.

Sob estas considerações, este estudo objetivou analisar as repercussões biopsicossociais de uma capacitação realizada por um PEF sobre assuntos referentes às PCAF na saúde e afetividade de profissionais em uma USF.

\section{MATERIAL E MÉTODOS}

\section{TIPO DE ESTUDO}

Trata-se de um estudo de campo exploratório de caráter qualitativo, uma vez que almeja fornecer informações que permitam uma maior familiaridade com o problema estudado, tornando-o mais explícito por meio do aprofundamento de questões relacionadas a ele (GIL, 2002).

\section{CENÁRIO DO ESTUDO}

O estudo foi desenvolvido em uma USF, vinculada à ESF do município de São Carlos/SP, composta por duas equipes, cada uma apresentando profissionais de referência com atuação integral no referido serviço, abrangendo médico de família, enfermeiro, auxiliares de enfermagem, ACS, cirurgião dentista, auxiliar de consultório dentário e 
funcionário terceirizado da limpeza. Outros estudantes da graduação como fisioterapeutas, gerontólogos, médicos e psicólogos também atuavam neste equipamento, de forma pontual e itinerante.

\section{POPULAÇÃO DO ESTUDO}

No presente estudo foi utilizado o critério de amostragem deliberada por variedade de tipos, o qual consiste em uma escolha pelo pesquisador daqueles sujeitos que devido as suas características pessoais melhor contribuirão para a compreensão do tema abordado (TURATO, 2003). Dessa forma, os nove sujeitos selecionados possuíam uma característica comum específica diretamente vinculada ao objetivo da pesquisa, isso é, todos haviam participado da capacitação ofertada anteriormente, denominada grupo "Para Nossa Alegria", e ainda atuavam na referida USF, a saber: oito ACS e uma funcionária terceirizada da limpeza (TL), totalizando a amostra deste estudo.

Foram excluídos três indivíduos que, embora tenham participado da capacitação, não mais atuavam como profissionais na referida USF.

\section{GRUPO "PARA NOSSA ALEGRIA"}

O grupo "Para Nossa Alegria" originou-se da demanda trazida por alguns profissionais da USF em questão a respeito da carência de informações, conhecimentos e, consequentemente, segurança em relação à orientação das PCFA aos usuários deste equipamento. Com isso, ele foi criado a fim de capacitar estes indivíduos por meio de atividades lúdicas e práticas corporais com a supervisão de um PEF integrante do Programa de Residência Multiprofissional em Saúde da Família e Comunidade da Universidade Federal de São Carlos juntamente com outros residentes que fizeram parte deste programa (dentista, enfermeiras e terapeuta ocupacional).

Inicialmente, a proposta foi apresentada e discutida em reunião de equipe envolvendo todos os profissionais a fim de analisar sua viabilidade, definir as melhores datas e horários para sua execução e identificar os assuntos mais pertinentes.

A Educação Física oferece uma ampla gama de possibilidades que visa o movimento corporal. Assim, para a escolha dos temas, foram utilizados como referências os Parâmetros Curriculares Nacionais da Educação Física (BRASIL, 1997b), os quais trazem como eixos temáticos os esportes, jogos, lutas e ginásticas, atividades rítmicas e expressivas e de conhecimentos sobre o corpo.

Portanto, buscando trabalhar as múltiplas facetas que a Educação Física pode apresentar, os temas selecionados foram agrupados em três blocos de quatro encontros cada (Quadro 1). 
Quadro 1 - Descrição do programa de capacitação em atividades físicas na USF do estudo

\begin{tabular}{l|l}
\hline \multicolumn{1}{c}{ BLOCOS } & \multicolumn{1}{c}{ OBJETIVOS DOS BLOCOS } \\
\hline \multirow{5}{*}{ Exercícios } & $\begin{array}{l}\text { Esclarecer os benefícios e malefícios decorrentes da prática habitual de exercícios } \\
\text { résicos resistidos (também chamados de exercícios de sobrecarga muscular). } \\
\text { Fornecer informações claras sobre indicações e contraindicações para a prática de } \\
\text { exercícios físicos resistidos. } \\
\text { Realizar pequenas sessões de exercícios físicos resistidos que trabalhem os } \\
\text { principais grupamentos musculares, visando à capacitação para a realização dos } \\
\text { mesmos de forma independente e autônoma fora de um ambiente de trabalho e com } \\
\text { os materiais disponíveis no momento. } \\
\text { Fornecer dicas de quais exercícios físicos resistidos realizar com determinadas } \\
\text { populações (ex.: idosos e gestantes), bem como a melhor forma de execução dos } \\
\text { mesmos, de forma a garantir suprimentos suficientes para a execução de grupos } \\
\text { futuros. }\end{array}$ \\
\hline $\begin{array}{l}\text { Trabalhar a cooperação dentro da equipe. } \\
\text { Trabalhar a competitividade de forma saudável. } \\
\text { Trabalhar as características biopsicossociais decorrentes deste tipo de atividade. } \\
\text { Realizar diferentes atividades e fornecer dicas de como aplicá-las, visando à } \\
\text { capacitação e a segurança para desenvolvê-las com determinadas populações (ex.: } \\
\text { crianças e idosos), de forma a garantir suprimentos suficientes para a execução de } \\
\text { grupos futuros. }\end{array}$ \\
\hline $\begin{array}{l}\text { Esclarecer os benefícios decorrentes da prática habitual de alongamentos, } \\
\text { ressaltando também a questão da flexibilidade. } \\
\text { Fornecer informações claras sobre as melhores formas de execução, assim como os } \\
\text { ambientes propícios e os momentos adequados. } \\
\text { Mostrar e vivenciar a prática de alongamentos no próprio ambiente de trabalho, } \\
\text { visando fornecer subsídios para que esta seja incorporada no dia-a-dia sem que } \\
\text { demande um tempo adicional na rotina do indivíduo. } \\
\text { Realizar pequenas sessões de alongamentos visando não somente a aplicação dos } \\
\text { conceitos trabalhados como também o relaxamento por parte da equipe. } \\
\text { De uma forma geral: englobar os principais aspectos que permitem uma prática } \\
\text { consistente de alongamentos para que a mesma possa estar inserida em grupos } \\
\text { existentes ou futuros por parte de membros da equipe envolvidos neles. }\end{array}$ \\
\hline
\end{tabular}

Apesar da demanda por mais assuntos, como massagem, exercícios aeróbicos, treinamento funcional, equilíbrio, artes circenses, lutas e danças, uma mudança no processo de trabalho pelos gestores municipais, acarretou na indisponibilidade do horário para o desenvolvimento do grupo, interrompendo o momento de capacitação dos profissionais, com consequente encerramento das atividades.

\section{COLETA DE DADOS}

Para a coleta de dados foi realizada uma entrevista semidirigida elaborada especificamente para este estudo, composta por duas partes, sendo: Parte I Características sociodemográficas do profissional e; Parte II - Repercussões da capacitação.

Cada qual foi gravada e, posteriormente, transcrita na íntegra. As respostas foram mantidas sem alterações/correções com o objetivo de preservar o discurso genuíno dos sujeitos. Após a transcrição, cada entrevista foi submetida ao processo de conferência de 
fidedignidade (DUARTE, 2004).

Os profissionais foram abordados em seus próprios locais de trabalho durante horário de expediente e dispuseram do tempo necessário para responder de forma individual, anônima e reservada à entrevista em um ambiente calmo e silencioso a fim de evitar interferências que pudessem atrapalhar ou comprometer a qualidade do conteúdo abordado. Foi valorizada a autonomia dos entrevistados de forma a permitir um livre posicionamento perante as questões apresentadas.

\section{ANÁLISE DOS DADOS}

Para a análise e interpretação dos dados foi utilizada a análise de conteúdo temático apoiada no referencial teórico do cuidando do cuidador mediante trajetória ideográfica-nomotética, ou seja, partindo-se dos discursos individuais (ideográficos) construiu-se o coletivo (nomotético) que representou as ideias dos indivíduos (GARNICA, 1997). Esse procedimento compreende três etapas: pré-análise, organização dos achados segundo categorias temáticas ou categorização e interpretação (MINAYO, 2010; TURATO, 2003).

Durante a fase de pré-análise, foi feita a leitura flutuante de todas as entrevistas realizadas com o objetivo de apreender o conteúdo explícito (TURATO, 2003), o que contribuiu para a formação do universo estudado em sua integralidade e permitiu a identificação dos temas abordados pelos entrevistados, os quais futuramente constituíram as categorias temáticas deste estudo (MINAYO, 2010).

$\mathrm{Na}$ fase de categorização, dois critérios foram utilizados para a definição das categorias instituídas: repetição e relevância, sendo o primeiro correspondente a frequência que cada colocação apareceu e o segundo referente aos pontos apresentados pelos entrevistados que não necessariamente foram repetidos, mas que representaram falas que refutaram ou corroboraram as hipóteses desse estudo (TURATO, 2003). Considerando isso, os dados brutos individuais foram transformados em um corpus coletivo de dados organizados em categorias temáticas, proporcionando a compreensão das falas dos sujeitos (TURATO, 2003).

Por fim, tendo as categorias temáticas já definidas, na fase de interpretação, também chamada de hermenêutica, foram realizadas inferências que possibilitaram a produção de contribuições frente ao objeto de estudo com base no referencial teórico adotado (TURATO, 2003). 


\section{RESULTADOS E DISCUSSÃO}

\section{CARACTERIZAÇÃO DOS PARTICIPANTES}

Nove dos doze profissionais que anteriormente compuseram o grupo "Para Nossa Alegria" ainda atuavam na referida USF, totalizando a amostra deste estudo. As características sociodemográficas de cada voluntário estão representadas no Quadro 2. Os participantes foram identificados pela letra "P" seguida de um número determinado pela sequência da realização das entrevistas.

Quadro 2 - Características sociodemográficas dos participantes

\begin{tabular}{ccccc}
\hline Identificação & Idade (anos) & Sexo & Cargo USF & Atuação USF (anos) \\
\hline P1 & 33 & $\mathrm{~F}$ & ACS & 7 \\
P2 & 30 & $\mathrm{~F}$ & TL & 11 \\
P3 & 27 & $\mathrm{~F}$ & ACS & 4 \\
P4 & 30 & $\mathrm{~F}$ & ACS & 4 \\
P5 & 40 & $\mathrm{~F}$ & ACS & 5 \\
P6 & 31 & F & ACS & 6 \\
P7 & 28 & F & ACS & 7 \\
P8 & 30 & F & ACS & 7 \\
P9 & 41 & F & ACS & \\
\hline
\end{tabular}

USF: Unidade de Saúde da Família; ACS: Agente Comunitário de Saúde;

TC: Terceirizada da limpeza

Nenhum dos voluntários realizou capacitações envolvendo PCAF após o término do grupo "Para Nossa Alegria".

\section{OS TEMAS GERAIS ABORDADOS PELOS SUJEITOS}

O grupo "Para Nossa Alegria" não pretendeu aferir melhoras estéticas ou no rendimento físico e sim desenvolver ações buscando transformações das práticas profissionais e da organização do trabalho, mas devido ao caráter diferenciado de suas ações, extrapolou as questões técnicas e contribuiu, sobremaneira, para o fortalecimento da integridade biopsicossocial dos participantes, explorando espaços criativos e respeitando valores, crenças e objetivos individuais.

Assim sendo, os entrevistados abordaram as repercussões biopsicossociais decorrentes da capacitação, o que culminou no estabelecimento de duas categorias de análise que permitiram apresentar e discutir os resultados obtidos: "Saúde do trabalhador" e "Afetividade". Alguns excertos das entrevistas foram reproduzidos não somente com o intuito de ilustrar as teorias explicativas, mas também de fornecer subsídios para questionamentos de pressupostos e concepções teóricas consolidadas. 


\title{
Saúde do trabalhador
}

A participação no grupo "Para nossa Alegria" proporcionou situações de autocuidado dos profissionais da USF no âmbito psicológico:

\begin{abstract}
"Era um modo assim da gente dar uma desacelerada, porque a gente fica ali, já é um ambiente, às vezes, têm dias que tão pesado, tão carregado né, e aquilo no final da tarde dava um ânimo pra gente né, é como se fosse uma terapia mesmo. [...] Era um momento que todo mundo conseguia parar um pouco, sair um pouco daquela coisa pesada do agente que vai na casa e a visita é difícil daquele dia, é uma família complicada. Então quando era dias que tinha grupo, falava assim 'ai, que legal de ter um grupo, vou conseguir desfocar um pouco"' (P5).

"[...] era um momento que a gente tinha que eu considerava um momento que era 'cuidando do cuidador', um momento único, porque no dia a dia, na nossa casa é uma correria, no nosso trabalho a gente nunca para pra fazer isso e mesmo quando a gente participa de uma atividade como um grupo de caminhada, tudo, é um cuidado que você tá direcionando pros outros, você não se observa, você não presta atenção em você mesmo, então o grupo "Para Nossa Alegria" era um grupo que a gente tinha... Que era só nosso, naquele momento a gente não se preocupava com mais ninguém, com mais nada, a não ser com nós mesmos. Era divertido, além da gente trabalhar o físico, acho que trazia uma certa paz de espírito, a gente brincava né e era um momento de descontração e pra mim era um momento muito bom [...] era um momento que a gente tentava escapar a pressão né, era um momento que a gente deixava sair tudo pra fora, de alguma maneira se sentir leve [...] era um momento onde a gente se esvaziava [...]" (P9).
\end{abstract}

Como trazido por Tamayo (2001), o estresse ocupacional é resultante da combinação do ambiente de trabalho com as características pessoais do profissional, ou seja, quando as obrigações laborais superam a capacidade que o trabalhador tem de enfrentá-las, tal estresse se torna evidente, caracterizando o trabalho na ESF como desorganizado, com atividades ineficientes, redução da produtividade e comunicação deficitária entre os membros da equipe, o que reflete diretamente na atenção dispendida aos usuários (CAMELO; ANGERAMI, 2004). Estudo realizado por Camelo e Angerami (2004) sinaliza que os ACS compõem um das categorias profissionais com maior risco de ser acometida por tal estresse, uma vez que ao serem obrigados a residir nos territórios de abrangência de seu equipamento, acabam por vivenciar de forma mais intensa o cotidiano daquela comunidade, necessitando de formações e preparos específicos para lidar com os entraves apresentados no dia-a-dia.

Tendo em vista a necessidade em lidar com essa questão, a prática habitual de atividade física tem se apresentado como uma ferramenta potencial para o aumento da tolerância ao estresse ocupacional (VAN CDOORNEN; DE GEUS, 1993; TAYLOR apud TAMAYO, 2001), tanto pela contribuição na redução da taxa de substâncias relacionadas a ele na corrente sanguínea (CREWS; LANDERS, 1987) quanto pela interação social que a atividade física permite aos seus praticantes (KOBASA, 1979).

Embora com menor frequência, benefícios percebidos nos âmbitos físico e fisiológico também foram relatados:

"O que foi bom no grupo foi que ajudou na perda de peso né, eu emagreci, perdi cinco quilos. Melhorou bastante coisa, até no respirar, no andar, melhorou no agachar, no levantar" (P2). 
"Do grupo pra cá eu melhorei muito minha postura; desde o dia que vocês passaram os negócios da recepção, a melhor forma de abaixar pra pegar prontuário, é uma coisa que eu nunca esqueço, então eu sempre tento abaixar assim. Foi útil, muito útil” (P3).

O primeiro excerto corrobora com o estudo de Matsudo e Matsudo (2000), no qual os autores afirmam que um dos principais benefícios antropométricos advindo da prática de atividade física é a diminuição da gordura corporal, acarretando em melhor desempenho das atividades cotidianas e laborais. Já o segundo, vai ao encontro do trabalho de Albuquerque et al. (2010), no qual os autores sinalizam que a ausência da prática habitual de atividade física ocasiona alterações posturais negativas, refletindo diretamente na performance diária.

Além disso, é de conhecimento que a rotina dos serviços de saúde engloba, em sua grande maioria, situações que provocam modificações na plenitude emocional e psíquica dos profissionais envolvidos no ato de cuidar do próximo (OLINISKI; LACERDA, 2006), a exemplo de relacionamentos interpessoais com outros membros da equipe, vivência de situações inesperadas e adversas e contato com a dor e o sofrimento dos pacientes (HOGA apud OLINISKI; LACERDA, 2006), contribuindo para que este trabalhador adote posturas rígidas de defesa ou enfrentamento que poderão acarretar em desvalorização do cuidado tanto pessoal quanto profissionalmente (OLINISKI; LACERDA, 2006), já que o contato corriqueiro com seres humanos desperta nele seus próprios conflitos e frustrações (MARTINS, 2003). Entretanto, como explanado por Martins (2003), a pessoa que se dispõe a cuidar do seu semelhante não pode se esquecer de primeiramente cuidar de si, porém, muitas vezes, é renegado que esse cuidador também necessita receber cuidado.

Nesse sentido, Oliniski e Lacerda (2006) apontam para a necessidade que os equipamentos de saúde têm de ofertarem espaços para o cuidado dos profissionais encarregados de cuidar do próximo, uma vez que essa ação desenvolvida no local de trabalho, com grande chance, promoverá o bem-estar destes trabalhadores e, consequentemente, melhoria da qualidade dos serviços ofertados aos usuários. Em complemento, este ambiente deve ser agradável e proporcionar, dentre alguns fatores, crescimento, alívio e proteção, uma vez que esses indivíduos lidam cotidianamente com situações de sofrimento, dor, tensão, tristeza, ansiedade, entre muitos outros (NEVES apud OLINISKI; LACERDA, 2006), características estas observadas no grupo "Para Nossa Alegria".

Apesar da constatação de tais benefícios e respectivas relevâncias, motivos políticos acarretaram no encerramento da ação, gerando grandes descontentamentos, ainda mais considerando que nenhuma outra proposta visando o bem-estar do trabalhador foi desenvolvida após o término do grupo "Para Nossa Alegria".

"Achei que quando acabou deu assim, deu saudade sabe? Podia continuar, ter mais um ciclo, não sei, porque foi importante, foi legal. Eu ainda sinto falta de tipo, se isso tivesse tido uma continuidade, pra gente tirar as dúvidas mesmo, aprender mais coisas, eu acho que seria interessante pro usuário e pra gente também, porque desmotiva muito você não 
ter algo novo pra trazer, ficar só naquela mesmice" (P1).

"Só que eu penso que esse tipo de trabalho teria que ser contínuo né, e se para morre, acaba. Junto com isso, acaba aquilo que tava te trazendo qualidade também, se acaba definitivamente né. Acho que deveria existir grupos dessa forma, mas contínuos sabe? Porque os problemas vêm, as dores vêm, o cansaço vem, a estafa vem; você tem que ter alguma coisa pra escapar da pressão sempre, então pra mim era um grupo muito bom, muito divertido, com muita dinâmica e muita educação voltada às práticas diárias mesmo né, do nosșo dia a dia, as coisas que a gente podia tá mudando e melhorando no nosso dia a dia. É uma pena que hoje não tem quase movimento nenhum voltado pra nós que somos servidores né, estamos aqui só servindo, mas uma hora a gente precisa ser servido também, como qualquer ser humano" (P9).

\section{Afetividade}

Entende-se que o trabalho em equipe de saúde demanda comunicação cotidiana entre os profissionais e compartilhamento de suas ações e saberes, propiciando a formação de vínculos que reflete em maior aceitação do outro enquanto sujeito autônomo e pensante (CIAMPONE; PEDUZZI, 2000). Nesse sentido, aqueles que participaram da capacitação relataram, em diversos momentos, como esta foi importante para promover união da equipe devido à aproximação de trabalhadores que, embora atuem em um mesmo ambiente, muitas vezes não conseguem conversar e interagir.

"Eu senti que eu consegui me entrosar com algumas pessoas que, às vezes, eu não tenho tanto contato, mesmo vendo todos os dias" (P1).

"[...] ajudou no convívio com as pessoas, porque você acaba convivendo mais, você acaba aprendendo com as pessoas, ajudava bastante, porque você acaba se entretendo com as pessoas que você não conversa, que no convívio do seu trabalho você acaba nem conversando, daí na atividade você acaba criando mais vínculo" (P2).

"Se a gente for parar e pensar, a gente passa mais tempo com o pessoal aí dentro, não só com os usuários, mas com os outros funcionários do que com a nossa família em casa. Então assim, claro, ali acontecem algumas discórdias, têm algumas desavenças né, algumas coisas que eu concordo e você não... Então assim, às vezes, é legal algum tipo de atividade assim pra fazer a gente parar um pouco e pensar no outro sabe, falar 'não, peraí"' (P5).

A união da equipe é importante, sobretudo na ESF, pois se faz necessária a presença de uma equipe multiprofissional entrosada para melhor proporcionar a integralidade do cuidado aos usuários (ARAÚJO; ROCHA, 2007), uma vez que este é um dos princípios doutrinários do SUS e consiste em ações preventivas e curativas em todos os níveis de complexidade do sistema (BRASIL, 1990) viabilizadas pelo trabalho conjunto de profissionais de diversas áreas.

Porém, é importante salientar que apenas ter uma equipe multiprofissional atuando em um mesmo espaço físico não é suficiente para modificar o tipo de cuidado ofertado aos pacientes (ARAÚJO; ROCHA, 2007); é necessário tomar condutas que de fato proporcionem a transformação das práticas profissionais, oportunizando a interação e a troca de conhecimentos entre os trabalhadores (ARAÚJO; ROCHA, 2007). Nesse sentido, a atividade física desempenhada de forma lúdica pode se mostrar como uma ferramenta com grande potencial, já que por meio da ludicidade, as pessoas podem se expressar 
livremente, além de conhecer e transformar a própria realidade.

\section{CONSIDERAÇÕES FINAIS}

A constatação de repercussões na saúde e afetividade de profissionais que participaram do grupo "Para Nossa Alegria", uma capacitação teórico-prática em PCAF, são os principais achados deste estudo.

Esses resultados justificam a adoção de uma ação mais ampla envolvendo novas capacitações, tanto no âmbito local da USF em questão quanto nos demais equipamentos de saúde da rede assistencial de atenção primária, a qual poderia ser ofertada pelo PEF integrante do NASF que, até então não estava disponível no município de São Carlos.

A ampliação da abrangência dessa capacitação pode proporcionar um empoderamento dos profissionais da ESF no que diz respeito à promoção em saúde e prevenção de agravos, em especial na ação específica de PCAF. O envolvimento destes no incentivo à adoção de atividades físicas como hábito de vida saudável pela população reflete em maior integralidade do cuidado, levando os benefícios da prática para uma maior parcela de indivíduos.

Em outro âmbito, tendo a capacitação uma parte prática que viabiliza a vivência de PCAF aos profissionais de saúde, concomitantemente proporcionando bem-estar por meio de benefícios biopsicossociais, subentende-se melhora indireta na integralidade das ações destinadas aos usuários dos serviços, pois estando o trabalhador melhor consigo mesmo, existe maior probabilidade de se dedicar ao próximo.

Entretanto, a implementação dessa capacitação como uma estratégia municipal, estadual ou nacional deve ser adotada levando-se em consideração a barreira de adesão dos profissionais. Nesse sentido, é importante pensar em mecanismos que incentivem maior participação dos trabalhadores, como estabelecer um horário semanal para o cuidado laboral com a equipe, pois promoção, prevenção, cura e reabilitação devem ser realizadas por todos os membros da equipe.

Além disso, no que diz respeito às PCAF, os conceitos e conhecimentos mudam com determinada periodicidade, sendo necessária uma atualização mais frequente dos temas, uma vez que as demandas dos serviços de saúde são inúmeras e aumentam a cada dia, não favorecendo que o trabalhador renove seu repertório sozinho, o que implica na necessidade da recondução da capacitação proposta.

Ainda, devido ao fato de este projeto ter sido desenvolvido em uma ESF em que seus membros criaram laços de afetividade com a pesquisadora principal, as respostas aqui apresentadas podem conter traços dessa relação harmoniosa, comprometendo, em partes, a subjetividade do estudo, o que representa uma limitação do mesmo. Por outro lado, reforça a importância da afetividade neste ambiente de trabalho.

Por fim, é esperado que os benefícios obtidos com essa capacitação reflitam na 
qualidade do cuidado ofertado aos usuários pertencentes ao território adscrito da USF. Porém, no presente estudo, embora os profissionais tenham sido capacitados de forma a se tornarem multiplicadores dos temas abordados, os efeitos diretos com a população não foram avaliados. Assim sendo, pesquisas futuras devem ser incentivadas objetivando constatar se, de fato, o investimento na capacitação em PCAF para ESF beneficiarão a integralidade da atenção prestada ao paciente. Uma possibilidade para se atingir tal objetivo seria averiguar diretamente com os usuários mudanças referentes ao perfil das doenças previamente instaladas, modificações em condutas que englobem questões afetivas e emocionais e melhoras da qualidade de vida de forma geral após iniciarem as PCAF.

\section{REFERÊNCIAS}

ALBUQUERQUE, Plínio Luna de. et al. Interferência da prática de atividade física habitual na postura de jovens. Terapia Manual, v. 8, n. 37, p. 198-203. 2010. Disponível em: $<$ https://www.researchgate.net/publication/280713934>

ARAÚJO, Marize Barros de Souza; ROCHA, Paulo de Medeiros. Trabalho em equipe: um desafio para a consolidação da estratégia de saúde da família. Ciência \& Saúde Coletiva, Rio de Janeiro, v. 12, n. 2, p. 455-64. 2007. Disponível em: <http://dx.doi.org/10.1590/S1413-81232007000200022>

BRASIL. Conselho Nacional de Secretários de Saúde. Sistema Único de Saúde. Brasília, 2011.

. Lei no 8.080 , de 19 de setembro de 1990. Dispõe sobre as condições para promoção, proteção e recuperação da saúde, a organização e o funcionamento dos serviços correspondentes e dá outras providências. Diário Oficial da União, Brasília, DF, 20 set. 1990. Seção 1, p. 18055.

- Ministério da Saúde. Secretaria de Assistência à Saúde. Coordenação de Saúde da Comunidade. Saúde da Família: uma estratégia para a reorientação do modelo assistencial. Brasília, 1997a.

. Ministério da Saúde. Secretaria de Atenção à Saúde. Departamento de Atenção

Básica. Diretrizes do NASF: Núcleo de Apoio à Saúde da Família. Brasília, 2009.

. Ministério da Saúde. Secretaria de Atenção à Saúde. Departamento de Atenção

Básica. Política Nacional de Atenção Básica. Brasília, 2006.

. Ministério da Saúde. Secretaria de Vigilância em Saúde. Secretaria de Atenção à Saúde. Política Nacional de Promoção da Saúde. Brasília, 2010.

. Secretaria de Educação Fundamental. Parâmetros curriculares nacionais: Educação Física. Brasília, 1997b.

CAMELO, Silvia H. Henriques; ANGERAMI, Emília Luigia Saporiti. Sintomas de estresse nos trabalhadores atuantes em cinco núcleos de saúde da família. Revista Latino-

Americana de Enfermagem, Ribeirão Preto, v. 12, n. 1, p. 14-21, jan./fev. 2004. 
Disponível em: <http://dx.doi.org/10.1590/S0104-11692004000100003>

CIAMPONE, Maria Helena Trench; PEDUZZI, Marina. Trabalho em equipe e trabalho em grupo no programa de saúde da família. Revista Brasileira de Enfermagem, Brasília, v. 53, n. especial, p. 143-7, dez. 2000. Disponível em: <http://dx.doi.org/10.1590/S003471672000000700024>

CREWS, Debra J.; LANDERS, Daniel M. A meta-analytic review of aerobic fitness and reactivity to psychosocial stressors. Medicine \& Science in Sports \& Exercise, v. 19, n. 5 Suppl, p. S114-20, oct. 1987. Disponível em:

<https://www.ncbi.nlm.nih.gov/pubmed/3316910>

DUARTE, Rosália. Entrevistas em pesquisas qualitativas. Educar, Curitiba, n. 24, p. 213225. 2004.

FREITAS, Fabiana Fernandes de. A Educação Física no serviço público de saúde. São Paulo: Hucitec, 2007.

GARNICA, Antonio Vicente Marafioti. Algumas notas sobre pesquisa qualitativa e fenomenologia. Interface - Comunicação, Saúde, Educação, v. 1, n. 1, p. 109-22, ago. 1997. Disponível em: <http://dx.doi.org/10.1590/S1414-32831997000200008>

GIL, Antonio Carlos. Como elaborar projetos de pesquisa. 4. ed. São Paulo: Atlas, 2002.

HOGA, Luiza Akiko Komura apud OLINISKI, Samanta Reikdal; LACERDA, Maria Ribeiro. Cuidando do cuidador no ambiente de trabalho: uma proposta de ação. Revista Brasileira de Enfermagem, Brasília, v. 59, n. 1, p. 100-104, jan./fev. 2006. Disponível em: <http://dx.doi.org/10.1590/S0034-71672006000100019>

KOBASA, Suzanne, C. Stressful life events, personality and health: an inquiry into hardiness. Journal of Personality and Social Psychology, v. 37, n. 1, p. 1-11, jan. 1979. Disponível em: <https://www.ncbi.nlm.nih.gov/pubmed/458548>

MARTINS, Maria Cezira Fantini Nogueira. Humanização da assistência e formação do profissional de saúde. The International Journal of Psychiatry, v. 8, n. 5, mai. 2003. Disponível em: <http://www.polbr.med.br/ano03/artigo0503_1.php>

MATSUDO, Sandra Mahecha; MATSUDO, Victor Keihan Rodrigues; BARROS NETO, Turíbio Leite. Efeitos benéficos da atividade física na aptidão física e saúde mental durante o processo de envelhecimento. Revista Brasileira de Atividade Física \& Saúde, v. 5, n. 2, p. 60-76, abr./jun. 2000. Disponível em:

<https://periodicos.ufpel.edu.br/ojs2/index.php/RBAFS/article/view/1004>

MERHY, Emerson Elias. et al. O trabalho em saúde: olhando e experienciando o SUS no cotidiano. 4. ed. São Paulo: Hucitec, 2007.

MINAYO, Maria Cecília de Souza. O desafio do conhecimento: pesquisa qualitativa em saúde. 12. ed. São Paulo: Hucitec, 2010.

NEVES, Eloita Pereira apud OLINISKI, Samanta Reikdal; LACERDA, Maria Ribeiro. Cuidando do cuidador no ambiente de trabalho: uma proposta de ação. Revista 
Brasileira de Enfermagem, Brasília, v. 59, n. 1, p. 100-104, jan./fev. 2006. Disponível em: <http://dx.doi.org/10.1590/S0034-71672006000100019>

OLINISKI, Samanta Reikdal; LACERDA, Maria Ribeiro. Cuidando do cuidador no ambiente de trabalho: uma proposta de ação. Revista Brasileira de Enfermagem, Brasília, v. 59, n. 1, p. 100-104, jan./fev. 2006. Disponível em: <http://dx.doi.org/10.1590/S0034-71672006000100019>

TAMAYO, Alvaro. Prioridades Axiológicas, Atividade Física e Estresse Ocupacional. Revista de Administração Contemporânea, Curitiba, v. 5, n. 3, p. 127-47, set./dez. 2001. Disponível em: <http://dx.doi.org/10.1590/S1415-65552001000300007>

TAYLOR, Shelley E. apud TAMAYO, Alvaro. Prioridades Axiológicas, Atividade Física e Estresse Ocupacional. Revista de Administração Contemporânea, Curitiba, v. 5, n. 3, p. 127-47, set./dez. 2001. Disponível em: <http://dx.doi.org/10.1590/S141565552001000300007>

TURATO, Egberto Ribeiro. Tratado da metodologia da pesquisa clínico-qualitativa: construção teórico-epistemológica, discussão comparada e aplicação nas áreas da saúde e humanas. 2 ed. Petrópolis: Vozes, 2003.

VAN CDOORNEN, Lorenz J. P.; DE GEUS, Eco J. C. Stress, physical activity and coronary heart disease. Work \& Stress, v. 7, n. 2, p. 121-39. 1993. Disponível em: <https://doi.org/10.1080/02678379308257056> 